\title{
Relationship between the presence of baccalaureate-educated RNs and quality of care: a cross-sectional study in Dutch long- term care facilities
}

Ramona Backhaus ${ }^{1 *}$, Erik van Rossum ${ }^{1,2}$, Hilde Verbeek ${ }^{1}$, Ruud J. G. Halfens ${ }^{1}$, Frans E. S. Tan ${ }^{3}$, Elizabeth Capezuti ${ }^{4}$ and Jan P. H. Hamers ${ }^{1}$

\begin{abstract}
Background: Recent evidence suggests that an increase in baccalaureate-educated registered nurses (BRNs) leads to better quality of care in hospitals. For geriatric long-term care facilities such as nursing homes, this relationship is less clear. Most studies assessing the relationship between nurse staffing and quality of care in long-term care facilities are US-based, and only a few have focused on the unique contribution of registered nurses. In this study, we focus on BRNs, as they are expected to serve as role models and change agents, while little is known about their unique contribution to quality of care in long-term care facilities.
\end{abstract}

Methods: We conducted a cross-sectional study among 282 wards and 6,145 residents from 95 Dutch long-term care facilities. The relationship between the presence of BRNs in wards and quality of care was assessed, controlling for background characteristics, i.e. ward size, and residents' age, gender, length of stay, comorbidities, and care dependency status. Multilevel logistic regression analyses, using a generalized estimating equation approach, were performed.

Results: $57 \%$ of the wards employed BRNs. In these wards, the BRNs delivered on average 4.8 min of care per resident per day. Among residents living in somatic wards that employed BRNs, the probability of experiencing a fall (odds ratio 1.44; 95\% Cl 1.06-1.96) and receiving antipsychotic drugs (odds ratio 2.15; 95\% Cl 1.66-2.78) was higher, whereas the probability of having an indwelling urinary catheter was lower (odds ratio 0.70; 95\% Cl 0.53-0.91). Among residents living in psychogeriatric wards that employed BRNs, the probability of experiencing a medication incident was lower (odds ratio $0.68 ; 95 \% \mathrm{Cl} 0.49-0.95$ ). For residents from both ward types, the probability of suffering from nosocomial pressure ulcers did not significantly differ for residents in wards employing BRNs.

Conclusions: In wards that employed BRNs, their mean amount of time spent per resident was low, while quality of care on most wards was acceptable. No consistent evidence was found for a relationship between the presence of BRNs in wards and quality of care outcomes, controlling for background characteristics. Future studies should consider the mediating and moderating role of staffing-related work processes and ward environment characteristics on quality of care.

Keywords: Quality of care, Registered nurses, Nursing homes, Long-term care facilities, Staffing

\footnotetext{
*Correspondence: r.backhaus@maastrichtuniversity.nl

'Department of Health Services Research, Maastricht University, CAPHRI Care

and Public Health Research Institute, P.O. Box 6166200 MD Maastricht, The

Netherlands

Full list of author information is available at the end of the article
}

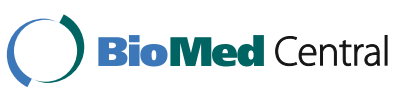

(c) The Author(s). 2017 Open Access This article is distributed under the terms of the Creative Commons Attribution 4.0 International License (http://creativecommons.org/licenses/by/4.0/), which permits unrestricted use, distribution, and reproduction in any medium, provided you give appropriate credit to the original author(s) and the source, provide a link to the Creative Commons license, and indicate if changes were made. The Creative Commons Public Domain Dedication waiver (http://creativecommons.org/publicdomain/zero/1.0/) applies to the data made available in this article, unless otherwise stated. 


\section{Background}

Recent evidence suggests that higher staffing levels and an increase in baccalaureate-educated registered nurses (BRNs) lead to better quality of care (QoC) in hospitals [1]. For long-term care facilities (LTCFs) such as nursing homes, this relationship is less clear [2, 3]. It is assumed that an increase in BRNs could lead to an improvement in quality of life and QoC for LTCF residents as well. However, in most countries, the number of BRNs in LTCFs is low [4]. Traditionally, working in LTCFs is associated with a low status career and inadequate salaries [5], reducing the chance to attract sufficient BRNs. When present BRNs currently often fulfill management positions. If involved in daily care, they frequently perform similar tasks as less educated staff. Their unique expertise could be used to serve as a role model, supervisor or innovator in the facility. As the number of less educated staff in LTCFs is high, BRNs can advance other staff practice to improve QoC $[2,4,6]$. The importance of BRNs in LTCFs, and especially in nursing homes, is expected to increase further as new models of care will likely be implemented in the near future that require high level coordination and evaluation skills [7], and BRNs are expected to have more of these abstract thinking skills than less educated staff [8].

International evidence for the added value of BRNs in LTCFs is scarce [2, 3]. Most studies assessing the relationship between nurse staffing and QoC in LTCFs are US-based [2, 3, 9], and only a few focus on the unique contribution of RNs [4, 10]. Most authors do not clarify the educational level of RNs, even though their educational backgrounds may differ substantially [11]. This study focuses on the unique contribution of BRNs in LTCFs. The aim of this study was to examine the relationship between the presence of BRNs in wards and QoC in Dutch LTCFs. As a national database on staffing and QoC is lacking in the Netherlands [12], we conducted this study in cooperation with the Dutch Prevalence Measurement of Care Problems (LPZ: Landelijke Prevalentiemeting Zorgproblemen) [13]. The LPZ measurement is an annual, multicenter, cross-sectional point prevalence measurement of several care problems in LTCFs (such as pressure ulcers and fall incidents).

In this study, we focus on nurse sensitive indicators of QoC. The relationship between the presence of BRNs in wards and outcomes that are most sensitive to nursing care is addressed. We chose the following five outcomes from the LPZ database: nosocomial pressure ulcers, medication incidents, falls, antipsychotic drug use, and urinary indwelling catheter use. Pressure ulcers are the most frequently used QoC outcome for assessing the relationship between nurse staffing and QoC in LTCFs and seem to be a nurse-sensitive outcome [2, 3]. Ideally, only nosocomial pressure ulcers, which are pressure ulcers that developed during a resident's stay in the LTCF, should be considered.

In previous studies, higher nurse staffing levels in LTCFs were associated with a decrease in falls [14-17], but evidence on the relationship between better educated staff and the occurrence of falls in LTCFs is lacking. In addition, evidence is absent for a relationship between the presence of RNs in wards and medication incidents in LTCFs. However, we expect that medication incidents can be seen as a nurse-sensitive outcome as RNs spend much time on medication-related activities $[18,19]$. Nevertheless, the occurrence of falls or medication incidents in LTCFs should be prevented as both can have serious consequences for residents, e.g. fall-related injuries or adverse drug events.

The prevalence rates of antipsychotic drug use in LTCFs are often high [20]. We assume that the high prevalence rates can partly be explained by the inappropriate use of antipsychotic drugs, associated with poor QoC [10, 20]. Antipsychotic drug use is defined as inappropriate when a clinical rationale is absent such as a diagnosis of delirium, schizophrenia, or psychotic disorder. Recent studies suggest that the prescription of antipsychotics is not based on clinical reasons alone, but that direct care staff in nursing homes often believe that antipsychotics are the only treatment choice to manage challenging resident behaviors including screaming, moaning or wandering $[20,21]$. The critical thinking skills of BRNs may place them in a better position to address challenging resident behavior without using antipsychotics, and might lead to less antipsychotic drug use on wards with higher BRN staffing levels.

Previous studies have considered fewer indwelling urinary catheters as a proxy for better urinary incontinence status of nursing home residents [2, 22, 23], and showed that more $\mathrm{RN}$ staff was associated with fewer catheterizations $[22,23]$. The use of urinary indwelling catheters should be prevented as they can cause urinary tract infections, resident discomfort, and decreased mobility $[10,24]$. BRNs are expected to have a better understanding of these negative consequences. Therefore, the prevalence rate of residents with indwelling urinary catheters might be lower on wards where BRNs are present.

\section{Methods \\ Study design}

This study was conducted in cooperation with the Dutch LPZ cross-sectional point prevalence measurement in April 2014. Annually, the LPZ measurement takes place on the same day in different health care settings. Participation of health care organizations is voluntary [13]. Data are collected at the organizational, ward, and resident level, using standardized questionnaires. Each 
participating organization appoints one coordinator who collects data at the organizational level, whereas ward managers provide data on their specific ward. Resident data (resident characteristics and prevalence of QoC outcomes) are collected by two health care professionals, one working on the resident's ward and one from another ward [13]. Inter-rater reliability between observers was found to be good (Cohen's kappa 0.87) $[13,25,26]$. The standardized questionnaires are based on psychometrically tested instruments, existing guidelines or literature reviews, and are developed and regularly updated in collaboration with experts [27-34].

To obtain BRN staffing data, we added 3 questions to the LPZ ward-level questionnaire. For each ward, the total number of hours of care delivered by BRNs was ascertained, as well as time spent in direct resident care (personal and nursing care, e.g. help with activities of daily living) and indirect care (e.g. staff education, coaching, and care innovation projects). No data were available on total nurse staffing.

\section{Setting and participants}

In Dutch LTCFs, most wards provide complex nursing care, whereas some wards provide only assistance with domestic tasks [35]. Typically, long-term nursing care for older adults in the Netherlands is provided in somatic (for residents with physical disabilities) and psychogeriatric (for residents with dementia) wards [36]. Therefore, we included only residents aged $>60$ years from psychogeriatric or somatic nursing care wards.

In the Netherlands, specifically trained nursing home medical specialists provide medical care for LTCF residents [36]. Both these specialists as well as associated health professionals (e.g. psychologists, physiotherapists) are employed by the LTCF. Similar to other countries, the educational level of nursing staff varies. The largest proportion of nursing staff consist of certified nurse assistants (educational level 3) with 2-3 years of vocational training [36]. Dutch certified nurse assistants are comparable to licensed practical/vocational nurses in the United States [37]. There are also nurse assistants (educational level 2), nurse aides (educational level 1) as well as some uneducated staff [38]. In many LTCFs, the lowest percentage of staff are RNs (educational level 4) and BRNs (educational level 5).

In total, 282 wards and 6,145 residents from 95 LTCFs were included in our study. The 95 LTCFs are managed by 20 Dutch elderly care organizations.

\section{Data source, variables and measurement}

Table 1 presents the study variables and their measurement.

\section{Resident characteristics and QoC outcomes}

Residents' age, gender, length of stay, number of comorbidities, and care dependency status (CDS) [39] were extracted from the LPZ, as well as the following QoC outcomes that were dichotomized (yes/no): nosocomial pressure ulcers, falls, antipsychotic drugs, medication incidents, and urinary indwelling catheters.

\section{Presence of BRN}

The total hours of care delivered by BRNs, as well as their hours spent on direct resident care and indirect care practices, were extracted from the LPZ. This data was used to distinguish between wards with at least one BRN present and wards that did not employ BRNs.

\section{Ward characteristics}

The ward type (somatic or psychogeriatric) as well as the ward size (number of residents living on ward) were extracted from the LPZ.

\section{Statistical analyses}

Data were analyzed with SPSS for Windows (version 22).

\section{Missing data}

In the Dutch LPZ, each participating organization can decide which QoC outcomes are assessed on the resident level within the organization [30]. Therefore, because of non-participation, data on QoC outcomes were partly missing. In addition, for some residents, data collectors were not able to determine whether or not the resident suffered from a QoC problem, leading to missing data as well. The latter was the case for nosocomial pressure ulcers $(n=22 ; 0.4 \%)$, falls $(n=53 ; 0.9 \%)$ and antipsychotic drug use $(n=28 ; 0.5 \%)$.

In total, among residents living in somatic wards, between $1.5 \%$ (falls) and $18.2 \%$ (nosocomial pressure ulcers) of data were missing. Among residents living in psychogeriatric wards, the amount of missing data ranged from $0.4 \%$ (falls) to $12.8 \%$ (nosocomial pressure ulcers). We cannot ignore these missing observations since the reasons for not including these by some organizations is not known. Therefore, three different approaches were taken to handle missing data. First, we performed a complete case analysis, ignoring missing data. Second, a sensitivity analysis was performed, in which all cases with missing data on a dependent variable were considered as "not suffering from the disease" (e.g., not having nosocomial pressure ulcers). Third, missing data were imputed, using multiple imputation techniques. To ensure the variability of predictors [40], the imputations were based on 7 (categorical) variables from the data set (BRNs working on ward, ward size, as well as residents' length of stay, age, gender, number of comorbidities, and care dependency). After performing 
Table 1 Study variables and their measurement

\begin{tabular}{|c|c|}
\hline Variable & Measurement \\
\hline \multicolumn{2}{|l|}{ Resident characteristics } \\
\hline Gender & Man/woman \\
\hline Age & Age in years \\
\hline Length of stay & Number of days \\
\hline Comorbidities & $\begin{array}{l}\text { Number of comorbidities (0-24a): Infectious illness; cancer; endocrine, nutritional or metabolic illness/disease; diabetes } \\
\text { mellitus; disease of blood or blood related organs; psychological disorders; dementia; nervous system disorder } \\
\text { (excluding cerebrovascular accident (CVA)); spinal cord lesion/paraplegia; cardio vascular disease; CVA/hemiparesis; } \\
\text { respiratory disorder/diseases, including nose and tonsils; disorder/disease of the digestive tract, including intestinal } \\
\text { obstruction, peritonitis, hernia, liver, gallbladder, pancreas; disorder/disease of kidney/urinary tract, sexual organs; skin } \\
\text { disorder/disease; motor disorder/disease; congenital disorders; injury resulting from accident (s), undesirable } \\
\text { consequences of accident (s); symptoms and abnormal clinical or lab findings, not elsewhere classified; overdose/ } \\
\text { substance abuse/addiction; disease of the eye; disease of the ear; pregnancy, child birth; external factors for disease }\end{array}$ \\
\hline Care dependency & $\begin{array}{l}\text { Care Dependency Scale [39]: } \\
\text { For each of the following } 15 \text { activities, the degree to which the resident is dependent upon } \\
\text { care provided by others is indicated on a } 5 \text {-point scale (completely dependent (1) - completely } \\
\left.\text { independent }(5)^{a}\right) \text { : eating and drinking, incontinence, body posture, mobility, day/night pattern, } \\
\text { getting dressed and undressed, body temperature, hygiene, avoiding danger, communication, } \\
\text { contact with others, sense of rules and values, daily activities, recreational activities, learning ability } \\
\text { [13]. For each resident, the total score (sum of } 15 \text { items) was divided by } 15 \text { to obtain a mean score. }\end{array}$ \\
\hline \multicolumn{2}{|l|}{ Presence of BRN } \\
\hline Presence of BRN & At least one BRN present in ward \\
\hline \multicolumn{2}{|l|}{ Quality of care outcomes } \\
\hline $\begin{array}{l}\text { Nosocomial pressure } \\
\text { ulcers }\end{array}$ & $\begin{array}{l}\text { Resident suffers from at least one nosocomial pressure ulcer category 2-4 (European } \\
\text { Pressure Ulcer Advisory Panel (EPUAP) \& National Pressure Ulcer Advisory Panel (NPUAP) [13, 41]): } \\
\text { - Category 2: Partial thickness } \\
\text { - Category 3: Full thickness skin loss } \\
\text { - Category 4: Full thickness tissue loss }\end{array}$ \\
\hline \multirow[t]{5}{*}{ Medication incidents } & $\begin{array}{l}\text { Resident had at least one medication incident during the last } 30 \text { days }{ }^{\text {b. }} \text { : } \\
\text { - Omitted dose }\end{array}$ \\
\hline & - Wrong dose \\
\hline & - Wrong time taken \\
\hline & - Wrong drug \\
\hline & - Wrong drug administration \\
\hline Falls & Resident has fallen at least once during last 30 days ${ }^{b}$ \\
\hline Antipsychotic drug use & Antipsychotic drug use during last 7 days ${ }^{b}$ \\
\hline $\begin{array}{l}\text { Indwelling urinary } \\
\text { catheter use }\end{array}$ & Resident has an indwelling urinary catheter in place at the time \\
\hline \multicolumn{2}{|l|}{ Ward characteristics } \\
\hline Ward type & Psychogeriatric/somatic nursing care ward \\
\hline Ward size & Number of residents living on ward \\
\hline
\end{tabular}

anderlined score is the most favorable score

banswered by resident or responsible nurse and/or indicated in resident file [13]

the sensitivity analyses and the multiple imputations, the findings of these analyses were compared with those from the complete-case analyses.

\section{Univariate descriptive statistics}

Univariate descriptive statistics were computed. Means and standard deviations were calculated for resident characteristics and BRN staffing. For QoC outcomes, percentages of residents suffering from the outcome were calculated (frequency distribution).

\section{(Multilevel) logistic regression analyses}

For each QoC outcome, we estimated the relationship between the presence of BRNs in wards and QoC controlling for background characteristics, i.e. ward size, and residents' age, gender, length of stay, number of comorbidities, and care dependency status.

As the average time spent by BRNs per resident was low, we chose to dichotomize the BRN staffing variable, i.e. BRN not working on ward and BRN working on ward. Five control variables were recoded into categorical 
variables to avoid sparse cells and for the ease of interpretation [42]. Ward size was recoded into 4 categories, i.e. fewer than 12 residents, 13-24 residents, 25-36 residents, more than 37 residents. Age was recoded into 4 categories, i.e. age 61-70, age 71-80, age 81-90, and age 91-110. Length of stay was recoded into 6 categories, i.e. 0-1 years, 1-2 years, 2-3 years, 3-4 years, 4-5 years, and longer than 5 years. The number of comorbidities was recoded into 5 categories: 1 comorbidity, 2 comorbidities, 3 comorbidities, 4 comorbidities, and 5 or more comorbidities. The total CDS score of each resident was changed into 1 of 5 categories (completely dependent (1) - completely independent (5)).

Due to differences in the care provided in somatic and psychogeriatric wards, separate analyses were performed among residents living in somatic and psychogeriatric wards. Ideally, to take into account possible correlations between residents living in the same ward and/or LTCF, 3-level logistic regression analyses should have been conducted in which residents were nested in wards and wards were nested in LTCFs. However, as some LTCFs were included with only one ward, it was not possible to conduct 3-level analyses examining the possible impact of wards and LTCFs simultaneously. These analyses led to estimation problems. Alternatively, two different 2level logistic regression analyses were performed using a generalized estimating equation (GEE) approach. In these multilevel analyses, residents (level 1) were nested in wards (level 2) or residents (level 1) were nested in LTCFs (level 2). To test the correlation within residents living in the same ward or in the same LTCF, the intraclass correlation coefficient (ICC) was considered. Additionally, for each QoC outcome, a general logistic regression analysis was conducted for the resident level, not taking into account any hierarchy of data.

\section{Ethical considerations}

All data were extracted from an existing database (LPZ), in which we received permission to conduct secondary analyses. The LPZ received ethical approval from the Medical Ethics Review Committee (METC) of the University Hospital Maastricht and Maastricht University.

\section{Results}

\section{Univariate descriptive statistics \\ Ward and resident characteristics}

From the 282 participating wards, 117 were somatic wards (2,604 residents) and 165 were psychogeriatric wards (3,541 residents). Resident's mean age was 84 years $(\mathrm{SD} \pm 8)$ and $73 \%$ of the residents were female. Their mean length of stay was 2.9 years (1057 days (SD \pm 1055)), and on average, residents had 3 comorbidities $(\mathrm{SD} \pm 1)$. The mean $\mathrm{CDS}$ was 2.4 $(\mathrm{SD} \pm 1.2)$, meaning that, on average, residents were functionally dependent.

\section{Presence of BRN}

$57 \%$ of the wards employed a BRN, who delivered, on average, $4.8 \mathrm{~min}$ of care per resident per day (0.08 nurse hours per resident per day (NHPRD), $\mathrm{SD} \pm 0.08)$. The BRN conducted direct care practices on $91 \%$ of the wards that employed a BRN, and indirect care practices on $80 \%$ of the wards. On wards where the BRN had direct care practices, the average time spent on these practices was $3.6 \mathrm{~min}$ per resident per day (0.06 NHPRD, $\mathrm{SD} \pm 0.07)$. On wards where the BRN had indirect care practices, the average time spent on these practices was $1.2 \mathrm{~min}$ per resident per day (0.02 NHPRD, $\mathrm{SD} \pm 0.02)$.

\section{QoC}

From the residents that participated in our study, on average, $2.6 \%$ suffered from nosocomial pressure ulcers (category $2-4), 10.4 \%$ had experienced a fall, and $5.3 \%$ a medication incident. $7.2 \%$ of the residents had an indwelling urinary catheter and $19.6 \%$ received antipsychotic drugs. Table 2 shows a considerable variation in prevalence rates among residents between somatic (more likely to have a nosocomial pressure ulcer, medication incident or indwelling urinary catheter) and psychogeriatric wards (more likely to fall or use antipsychotic drugs). When analyzing the relationship between the presence of BRNs in wards and nosocomial pressure ulcers

Table 2 Differences in resident characteristics and prevalence rates of quality of care outcomes among residents living in somatic and psychogeriatric wards

\begin{tabular}{|c|c|c|}
\hline & $\begin{array}{l}\text { Residents living } \\
\text { in somatic wards } \\
(n=2604)\end{array}$ & $\begin{array}{l}\text { Residents living } \\
\text { in psychogeriatric } \\
\text { wards ( } n=3541 \text { ) }\end{array}$ \\
\hline \multicolumn{3}{|l|}{ Resident characteristics } \\
\hline Age in years (mean, SD) ${ }^{a}$ & $83 \pm 9$ & $84 \pm 7$ \\
\hline Female $(\%)^{a}$ & 70 & 75 \\
\hline $\begin{array}{l}\text { Length of stay in years and } \\
\text { days (mean, SD) }\end{array}$ & $3.1(1132 \pm 1200)$ & $2.7(1002 \pm 930)$ \\
\hline $\begin{array}{l}\text { Number of comorbidities } \\
(\text { mean, SD) }\end{array}$ & $3 \pm 1$ & $3 \pm 1$ \\
\hline Care dependency (mean, SD) ${ }^{\mathrm{ab}}$ & $2.9 \pm 1.2$ & $2.1 \pm 1.1$ \\
\hline \multicolumn{3}{|l|}{ Quality of care outcomes } \\
\hline Nosocomial pressure ulcers (\%) & $3.4(n=2131)$ & $1.9(n=3086)$ \\
\hline Medication incidents (\%) ${ }^{a}$ & $6.2(n=2307)$ & $4.6(n=3451)$ \\
\hline Falls $(\%)^{a}$ & $7.6(n=2564)$ & $12.4(n=3528)$ \\
\hline Antipsychotic drug use (\%) & $15.2(n=2296)$ & $22.6(n=3434)$ \\
\hline $\begin{array}{l}\text { Indwelling urinary catheter } \\
\text { use }(\%)^{a}\end{array}$ & $11.7(n=2271)$ & $3.9(n=3143)$ \\
\hline
\end{tabular}

Note:

$S D$ standard deviation

${ }^{a}$ significantly different among residents living in somatic and psychogeriatric wards ( $p<.01$; independent samples $t$-test or chi-square)

${ }^{b}$ degree to which the resident is dependent upon care provided by others is indicated on a 5-point scale (completely dependent (1) - completely independent (5)) 
among residents living on psychogeriatric wards, residents who were completely independent (i.e., $C D S 5 ; n=92$ ) were excluded, as none of these residents suffered from nosocomial pressure ulcers.

\section{(Multilevel) logistic regression analyses}

For each QoC outcome, the results of the multilevel and the general logistic regression analyses were almost identical, and the ICC was low. In addition, the results of complete case analyses and those from the sensitivity analyses, as well as the analyses with imputed data were almost identical. Therefore, we present only the results of the general logistic regression analyses for complete cases (Table 3).

As indicated in Table 3, among residents living in somatic wards that employed BRNs, the probability of experiencing a fall (odds ratio 1.44; 95\% CI 1.06-1.96) and receiving antipsychotic drugs (odds ratio 2.15; $95 \%$ CI 1.66-2.78) was higher, whereas the probability of having an indwelling urinary catheter was lower (odds ratio 0.70; 95\% CI 0.53-0.91). Among residents living in psychogeriatric wards that employed BRNs, the probability of experiencing a medication incident was lower (odds ratio $0.68 ; 95 \%$ CI $0.49-0.95$ ). For residents from both ward types, the probability of suffering from nosocomial pressure ulcers did not significantly differ for residents living in a ward that employed BRNs. In addition, among residents living in somatic wards, the probability of experiencing a medication incident did not significantly differ for residents living in a ward that employed BRNs. Among residents living in psychogeriatric wards, the probability of experiencing a fall, receiving antipsychotic drugs, or having an indwelling urinary catheter did not significantly differ for residents living in a ward that employed BRNs.

\section{Discussion and conclusions}

In our study, there was no consistent relationship found between the presence of BRNs in wards and several QoC indicators, controlling for background characteristics. Among residents living in somatic wards that employed BRNs, an increased probability of experiencing a fall and receiving antipsychotic drugs was found, and a decreased probability of having an indwelling urinary catheter. No significant differences were detected for nosocomial pressure ulcers and medication incidents. For residents living in psychogeriatric wards that employed BRNs a decreased probability of experiencing a medication incident was found, whereas the probability for developing any of the other QoC outcomes did not significantly differ.

Two systematic reviews also reported inconsistent findings on QoC indicators [2, 3]. For this study, there are several factors that need to be taken into consideration. First, only $57 \%$ of the wards employed a BRN, who delivered, on average, $4.8 \mathrm{~min}$ of care per resident per day. BRN staffing levels may not have been high enough to establish better QoC outcomes. For comparison, in a recent Swiss study among 402 wards from 155 nursing homes, on average $32 \%$ of all full-time equivalents (FTEs) per ward were RNs [43]. In a recent US study among nursing homes in Colorado [10], RNs spent on average $36 \mathrm{~min}$ of care per resident per day. As with all other studies examining the relationship between RN staffing and QoC, both studies did not indicate the educational background of RNs.

Second, for residents living in both types of wards, the prevalence of QoC problems seems low compared to studies conducted in other countries. However, differences in operationalization and measurement methods have to be considered when comparing prevalence rates to other studies [44], making comparisons difficult [26]. The

Table 3 Associations between presence of BRNs and quality of care indicators ${ }^{a}$

\begin{tabular}{|c|c|c|c|c|}
\hline Outcome measure & Ward type & OR (BRN on ward vs. no BRN on ward) & $95 \% \mathrm{Cl}$ & $p$-value \\
\hline \multirow[t]{2}{*}{ Nosocomial pressure ulcers } & Somatic & 0.68 & $0.42-1.10$ & .12 \\
\hline & Psychogeriatric & 0.79 & $0.46-1.38$ & .41 \\
\hline \multirow[t]{2}{*}{ Medication incidents } & Somatic & 1.17 & $0.82-1.67$ & .39 \\
\hline & Psychogeriatric & 0.68 & $0.49-0.95$ & .02 \\
\hline \multirow[t]{2}{*}{ Falls } & Somatic & 1.44 & $1.06-1.96$ & .02 \\
\hline & Psychogeriatric & 1.10 & $0.89-1.36$ & .38 \\
\hline \multirow[t]{2}{*}{ Antipsychotic drug use } & Somatic & 2.15 & $1.66-2.78$ & .00 \\
\hline & Psychogeriatric & 1.06 & $0.89-1.26$ & .51 \\
\hline \multirow[t]{2}{*}{ Urinary indwelling catheter use } & Somatic & 0.70 & $0.53-0.91$ & .01 \\
\hline & Psychogeriatric & 0.96 & $0.64-1.43$ & .83 \\
\hline
\end{tabular}

${ }^{a}$ Fully adjusted models estimating the relationship between the presence of BRNs and quality of care controlling for background characteristics, i.e. ward size, and residents' age, gender, length of stay, number of comorbidities, and care dependency status

Note:

$B R N$ s baccalaureate-educated registered nurses

$O R$ odds ratio

95\% Cl 95\% confidence interval around OR 
prevalence of nosocomial pressure ulcers was especially low, which may explain why the probability of suffering from nosocomial pressure ulcers did not significantly differ among residents living in wards that did or did not employ BRNs. For both ward types, antipsychotic drug use was the most prevalent QoC problem, yet the prevalence rate of $19.6 \%$ was low compared to prevalence rates in other countries. For example, in a study among Belgian nursing home residents the prevalence rate was 32.9\% [45]. Nevertheless, the fact that, in our sample, one resident out of every five was provided with antipsychotic drugs, could be a signal of inappropriate drug use. Only unnecessary antipsychotic drug use should be considered as poor QoC. In this study, we were not able to distinguish between (in)appropriate antipsychotic drug use.

Third, the practices of BRNs working in Dutch LTCFs may not differ from those conducted by other nursing staff, meaning that BRNs are not employed optimally to benefit from their unique contribution to QoC outcomes. It seems that most BRNs are responsible for multiple wards, which is reflected in the low amount of time spent per resident per day. BRNs might only see residents that are in acute, complex care situations (e.g., when a decision whether or not to hospitalize the resident has to be made), instead of looking at each resident's overall care plan.

The findings of this study should be interpreted carefully. The cross-sectional design provides no information about causality. For example, we cannot say whether the employment of BRNs in somatic wards led to an increased probability of receiving antipsychotic drugs or whether BRNs were employed due to high antipsychotic drug use. As some LTCFs were included with only one ward, it was not possible to conduct 3-level analyses examining the possible impact of wards and LTCFs simultaneously. Moreover, we had to focus on BRNs alone, not taking into consideration the contribution of other nursing staff, nursing home medical specialists and allied professionals working in Dutch LTCFs. In addition, due the low average amount of time BRNs spent on wards, we could only distinguish between wards that did or did not employ BRNs, not taking into consideration the actual amount of time BRNs worked on the wards. To compare BRN staffing among wards, we calculated NHPRDs. However, BRNs may only deliver care to residents with the most complex care problems. In our analyses, we distinguished between residents living in somatic and psychogeriatric wards, while in practice, the difference may not be that clear-cut, e.g., some residents living in somatic wards may suffer from dementia or residents living in psychogeriatric wards from somatic diseases as well. Finally, our analyses were limited to the QoC outcomes measured in the LPZ, while BRNs may influence other outcomes, e.g., outcomes related to quality of life of residents. Despite these limitations, our study is the first that provides insight into the relationship between the presence of BRNs in wards and QoC for Dutch LTCFs. As we made use of an existing data infrastructure (LPZ), the sample size was large (6145 residents), and collected data was of good quality.

Although the Dutch government is making efforts to increase the number of BRNs working in elder care, the number of BRNs working in LTCFs is still low, as in 43\% of the wards no BRNs were employed. Even for wards that employed BRNs, the mean amount of time spent per resident was low. For LTCFs it is therefore important to carefully think about how to best allocate BRNs on their wards. In recent years, there has been a call to shift emphasis back to the provision of essential nursing care, e.g., providing physical comfort and psychological support or establishing meaningful encounters between staff and residents [46, 47]. It might be the case that BRNs add particular value to improving essential nursing care, thus future studies should consider this. Recently, David Richards has posed the question whether nursing outcomes might need to be defined in terms of a concept called 'amalgamation of marginal gains' [47, 48]. During a hospital visit Richards experienced that small, individual actions by nurses only had marginal impact on his well-being, while in total, all these 'small actions' significantly reduced his feelings of discomfort and anxiety. By focusing on isolated components of essential nursing care (e.g., communication), Richards stresses one may miss the 'power of amalgamation' [47].

In our study, we focused on the presence of BRNs in wards rather than considering staffing as a 'multidimensional construct' [49]. Future studies should also consider the mediating and moderating role of staffing-related work processes and ward environment characteristics. For example, more BRNs in the mix of staff might lead to better teamwork and communication, that could result in better QoC $[17,50]$. Other examples of work processes BRNs might have influence on are the coordination of care [51], and the collaboration between nursing staff and nursing home medical specialists or allied health professionals [52]. In addition, BRNs might indirectly add value to $\mathrm{QoC}$ in LTCFs by acting as a clinical leader and coach for other nursing staff [53]. Moreover, BRNs might also have an influence on ward environment characteristics like the organizational culture or the team climate, which were associated with better QoC in previous studies [54, 55]. Conducting mixed methods-studies, e.g. by combining direct observations with stakeholder interviews, may help to obtain more information on observable behavior (e.g., interactions with residents or other staff and other 'small actions') and unobservable cognitive work of BRNs leading to added value for residents, family members, and staff [53]. 


\section{Abbreviations}

BRNs: Baccalaureate educated registered nurses; LTCFs: Long-term care facilities; NHPRD: Nurse hours per resident per day; QoC: Quality of care; RNs: Registered nurses

\section{Acknowledgements}

Not applicable.

\section{Funding}

The research project was funded by ZonMW (project number: 520001003), The Netherlands Organization for Health Research and Development. They had no role in study design, data collection, data analysis, decision to publish or the preparation of the manuscript.

\section{Availability of data and materials}

The data that support the findings of this study are available from the LPZ project group but restrictions apply to the availability of these data, which were used under license for the current study, and so are not publicly available. Data are however available from the authors upon reasonable request and with permission of the LPZ project group.

\section{Authors' contributions}

All authors were involved in the analysis and interpretation of data and critically reviewed the manuscript. RB, EvR, HV, RJGH, EC and JPHH were involved in the study design. FEST helped with statistical analyses. All authors read and approved the final manuscript.

\section{Authors' information}

Not applicable.

\section{Competing interests}

The authors declare that they have no competing interests.

\section{Consent for publication}

Not applicable.

\section{Ethics approval and consent to participate}

All data were extracted from an existing database (LPZ), in which we received permission to conduct secondary analyses. The LPZ received ethical approval from the Medical Ethics Review Committee (METC) of the University Hospital Maastricht and Maastricht University.

\section{Author details}

'Department of Health Services Research, Maastricht University, CAPHRI Care and Public Health Research Institute, P.O. Box 6166200 MD Maastricht, The Netherlands. ${ }^{2}$ Zuyd University of Applied Sciences, Research Centre on Autonomy and Participation, P.O. Box 5506400 AN Heerlen, The Netherlands. ${ }^{3}$ Department of Methodology and Statistics, Maastricht University, CAPHRI Care and Public Health Research Institute, P.O. Box 6166200 MD Maastricht, The Netherlands. ${ }^{4}$ Hunter College, City University of New York, Brookdale Campus West, Room 526, 425 E. 25th Street \# 925, New York, NY 10010, USA

Received: 22 September 2015 Accepted: 14 December 2016 Published online: 19 January 2017

\section{References}

1. Aiken LH, Sloane DM, Bruyneel L, Van den Heede K, Griffiths P, Busse R, Diomidous M, Kinnunen J, Kózka M, Lesaffre E, et al. Nurse staffing and education and hospital mortality in nine European countries: a retrospective observational study. Lancet. 2014;383(9931):1824-30.

2. Backhaus $R$, Verbeek H, van Rossum E, Capezuti E, Hamers JPH. Nurse staffing impact on quality of care in nursing homes: a systematic review of longitudinal studies. J Am Med Dir Assoc. 2014;15(6):383-93.

3. Spilsbury K, Hewitt C, Stirk L, Bowman C. The relationship between nurse staffing and quality of care in nursing homes: a systematic review. Int J Nurs Stud. 2011:48(6):732-50.

4. Weech-Maldonado R, Meret-Hanke L, Neff MC, Mor V. Nurse staffing patterns and quality of care in nursing homes. Health Care Manage Rev. 2004;29(2):107-16.

5. Tolson D, Rolland Y, Andrieu S, Aquino J, Beard J, Benetos A, Berrut G, CollPlanas L, Dong B, Forette F, et al. International association of gerontology and geriatrics: a global agenda for clinical research and quality of care in nursing homes. J Am Med Dir Assoc. 2011:12:184-9.

6. Boström AM, Rudman A, Ehrenberg A, Gustavsson J, Wallin L. Factors associated with evidence-based practice among registered nurses in Sweden: a national cross-sectional study. BMC Health Serv Res. 2013;13(1):165.

7. Auerbach DI, Staiger DO, Muench U, Buerhaus PI. The nursing workforce in an era of health care reform. N Engl J Med. 2013;368(16):1470-2.

8. Backhaus R, Verbeek H, van Rossum E, Capezuti E, Hamers JP. Future distinguishing competencies of baccalaureate-educated registered nurses in nursing homes. Geriatr Nurs. 2015;36(6):438-44.

9. Havig A, Skogstad A, Kjekshus L, Romoren T. Leadership, staffing and quality of care in nursing homes. BMC Health Serv Res. 2011;11(1):327.

10. Lee HY, Blegen MA, Harrington C. The effects of RN staffing hours on nursing home quality: a two-stage model. Int J Nurs Stud. 2014;51(3):409-17.

11. Hallberg IR, Cabrera E, Jolley D, Raamat K, Renom-Guiteras A, Verbeek H, Soto M, Stolt M, Karlsson S. Professional care providers in dementia care in eight European countries; their training and involvement in early dementia stage and in home care. Dementia. 2016;15(5):931-57.

12. Onder G, Carpenter I, Finne-Soveri H, Gindin J, Frijters D, Henrard J, Nikolaus T, Topinkova E, Tosato M, Liperoti R, et al. Assessment of nursing home residents in Europe: the Services and Health for Elderly in Long TERm care (SHELTER) study. BMC Health Serv Res. 2012;12(1):5.

13. van Nie-Visser NC, Schols JMGA, Meesterberends E, Lohrmann C, Meijers JMM, Halfens RJG. An International prevalence measurement of care problems: study protocol. J Adv Nurs. 2013;69(9):e18-29.

14. Hofmann MT, Bankes PF, Javed A, Selhat M. Decreasing the incidence of falls in the nursing home in a cost-conscious environment: a pilot study. J Am Med Dir Assoc. 2003:4(2):95-7.

15. Leland NE, Gozalo P, Teno J, Mor V. Falls in newly admitted nursing home residents: a national study. J Am Geriatr Soc. 2012:60(5):939-45.

16. Sandoval Garrido FA, Tamiya N, Kashiwagi M, Miyata S, Okochi J, Moriyama Y, Yamaoka Y, Takamuku K. Relationship between structural characteristics and outcome quality indicators at health care facilities for the elderly requiring long-term care in Japan from a nationwide survey. Geriatr Gerontol Int. 2014;14(2):301-8.

17. Schwendimann R, Zúñiga F, Ausserhofer D, Schubert M, Engberg S, de Geest S. Swiss nursing homes human resources project (SHURP): protocol of an observational study. J Adv Nurs. 2014;70(4):915-26.

18. Biron AD, Lavoie-Tremblay M, Loiselle CG. Characteristics of work interruptions during medication administration. J Nurs Scholarsh. 2009:41(4):330-6.

19. Keohane CA, Bane AD, Featherstone E, Hayes J, Woolf S, Hurley A, Bates DW, Gandhi TK, Poon EG. Quantifying nursing workflow in medication administration. J Nurs Adm. 2008;38(1):19-26.

20. van der Putten MJ, Wetzels RB, Bor H, Zuidema SU, Koopmans RT. Antipsychotic drug prescription rates among Dutch nursing homes: the influence of patient characteristics and the dementia special care unit. Aging Ment Health. 2014;18(7):828-32.

21. Lemay CA, Mazor KM, Field TS, Donovan J, Kanaan A, Briesacher BA, Foy S, Harrold LR, Gurwitz JH, Tjia J. Knowledge of and perceived need for evidence-based education about antipsychotic medications among nursing home leadership and staff. J Am Med Dir Assoc. 2013:14(12):895-900.

22. Castle NG, Anderson RA. Caregiver staffing in nursing homes and their influence on quality of care: using dynamic panel estimation methods. Med Care. 2011:49(6):545-52.

23. Horn S, Buerhaus P, Bergstrom N, Smout R. RN staffing time and outcomes of long-stay nursing home residents: pressure ulcers and other adverse outcomes are less likely as RNs spend more time on direct patient care. Am J Nurs. 2005;105(11):58-70.

24. Fakih MG, Krein SL, Edson B, Watson SR, Battles JB, Saint S. Engaging health care workers to prevent catheter-associated urinary tract infection and avert patient harm. Am J Infect Control. 2014;42(10, Supplement):S223-9.

25. Meijers JM, Candel MJ, Schols JM, Halfens RJ. Decreasing trends in malnutrition prevalence rates explained by regular audits and feedback. J Nutr. 2009:139(7):1381-6.

26. Meijers JM, Schols JM, van der Schueren MA vB-de, Dassen T, Janssen MA, Halfens RJ. Malnutrition prevalence in The Netherlands: results of the annual Dutch national prevalence measurement of care problems. Br J Nutr. 2009; 101(03):417-23.

27. Bours G, Halfens R, Lubbers M, Haalboom J. The development of a national registration form to measure the prevalence of pressure ulcers in The Netherlands. Ostomy Wound Manage. 1999;45(11):28. -33, 36-28, 40. 
28. Bours GJJW, Halfens RJG, Abu-Saad HH, Grol RTPM. Prevalence, prevention, and treatment of pressure ulcers: descriptive study in 89 institutions in The Netherlands. Res Nurs Health. 2002;25(2):99-110.

29. Dijkstra A, Buist G, Dassen T, Van den Heuvel W. Het meten van zorgafhankelijkheid met de ZorgAfhankelijkheidsSchaal, care dependency scale (CDS): een handleiding. Groningen: Noordelijk Centrum voor Gezondheidsvraagstukken, Rijksuniversiteit Groningen; 1999.

30. Halfens RJG, Meesterberends E, van Nie-Visser NC, Lohrmann C, Schönherr S, Meijers JMM, Hahn S, Vangelooven C, Schols JMGA. International prevalence measurement of care problems: results. J Adv Nurs. 2013;69(9):e5-e17.

31. Hannestad YS, Rortveit G, Sandvik H, Hunskaar S. A community-based epidemiological survey of female urinary incontinence: The Norwegian EPINCONT study. J Clin Epidemiol. 2000;53(11):1150-7.

32. Meijers JMM, van Bokhorst-de van der Schueren MAE, Schols JMGA, Soeters $P B$, Halfens RJG. Defining malnutrition: mission or mission impossible? Nutrition. 2010;26(4):432-40.

33. Neyens J, Dijcks B, van Haastregt J, de Witte L, van den Heuvel W, Crebolder $\mathrm{H}$, Schols J. The development of a multidisciplinary fall risk evaluation tool for demented nursing home patients in The Netherlands. BMC Public Health. 2006;6(1):74.

34. Thüroff JW, Abrams P, Andersson KE, Artibani W, Chapple CR, Drake MJ, Hampel C, Neisius A, Schröder A, Tubaro A. EAU guidelines on urinary incontinence. Eur Urol. 2011;59(3):387-400.

35. de Meijer C, Koopmanschap M, d' Uva TB, van Doorslaer E. Determinants of long-term care spending: Age, time to death or disability? J Health Econ. 2011;30(2):425-38.

36. Huls M, de Rooij SE, Diepstraten A, Koopmans R, Helmich E. Learning to care for older patients: hospitals and nursing homes as learning environments. Med Educ. 2015;49(3):332-9.

37. Verkaik R, Francke AL, van Meijel B, Spreeuwenberg PMM, Ribbe MW, Bensing JM. The introduction of a nursing guideline on depression at psychogeriatric nursing home wards: effects on certified nurse assistants. Int J Nurs Stud. 2011;48(6):710-9.

38. Willemse B, Depla M, Smit D, Pot A. The relationship between small-scale nursing home care for people with dementia and staff's perceived job characteristics. Int Psychogeriatr. 2014;26(05):805-16.

39. Dijkstra A, Yont GH, Korhan EA, Muszalik M, Kedziora-Kornatowska K, Suzuki M. The care dependency scale for measuring basic human needs: an international comparison. J Adv Nurs. 2012;68(10):2341-8.

40. Sterne JAC, White IR, Carlin JB, Spratt M, Royston P, Kenward MG, Wood AM, Carpenter JR. Multiple imputation for missing data in epidemiological and clinical research: potential and pitfalls. BMJ. 2009;338:b2393.

41. European Pressure Ulcer Advisory Panel and National Pressure Ulcer Advisory Panel. Prevention and treatment of pressure ulcers: quick reference guide. Washington DC: National Pressure Ulcer Advisory Panel;2009.

42. Zhang F, Lewis M, Yang G, Iriondo-Perez J, Zeng Y, Liu J. Apolipoprotein E polymorphism, life stress and self-reported health among older adults. J Epidemiol Community Health. 2008;62(4):e3.

43. Zúñiga F, Ausserhofer D, Hamers JPH, Engberg S, Simon M, Schwendimann R. Are staffing, work environment, work stressors, and rationing of care related to care workers' perception of quality of care? A cross-sectional study. J Am Med Dir Assoc. 2015. doi:10.1016/j.jamda.2015.04.012.

44. Schüssler S, Dassen T, Lohrmann C. Prevalence of care dependency and nursing care problems in nursing home residents with dementia: a literature review. Int J Caring Sci. 2014;7(2):338-52.

45. Azermai M, Elseviers M, Petrovic M, van Bortel L, Stichele RV. Assessment of antipsychotic prescribing in Belgian nursing homes. Int Psychogeriatr. 2011; 23(08):1240-8.

46. Kitson A, Conroy T, Kuluski K, Locock L, Lyons R. Reclaiming and redefining the fundamentals of care: Nursing's response to meeting patients' basic human needs. Adelaide: School of Nursing, the University of Adelaide; 2013.

47. Richards DA. Complex interventions and the amalgamation of marginal gains: a way forward for understanding and researching essential nursing care? Int J Nurs Stud. 2015;52:1143-5.

48. Cavendish M. Boy racer. New York: Random House; 2010.

49. Arling G, Mueller C. Nurse staffing and quality: the unanswered question. J Am Med Dir Assoc. 2014;15(6):376-8.

50. Colon-Emeric CS, McConnell E, Pinheiro SO, Corazzini K, Porter K, Earp KM Landerman L, Beales J, Lipscomb J, Hancock K, et al. CONNECT for better fall prevention in nursing homes: results from a pilot intervention study. J Am Geriatr Soc. 2013;61(12):2150-9.
51. Temkin-Greener H, Zheng N, Katz P, Zhao H, Mukamel DB. Measuring work environment and performance in nursing homes. Med Care. 2009;47(4):482-91.

52. Van Bogaert $P$, Timmermans $O$, Weeks SM, van Heusden D, Wouters K, Franck E. Nursing unit teams matter: Impact of unit-level nurse practice environment, nurse work characteristics, and burnout on nurse reported job outcomes, and quality of care, and patient adverse events-a cross-sectional survey. Int J Nurs Stud. 2014;51(8):1123-34.

53. Dellefield ME, Castle NG, McGilton KS, Spilsbury K. The relationship between registered nurses and nursing home quality: an integrative review (2008-2014). Nurs Econ. 2015;33(2):95-108.

54. Bower P, Campbell S, Bojke C, Sibbald B. Team structure, team climate and the quality of care in primary care: an observational study. Qual Saf Health Care. 2003;12(4):273-9.

55. van Beek AP, Gerritsen DL. The relationship between organizational culture of nursing staff and quality of care for residents with dementia: questionnaire surveys and systematic observations in nursing homes. Int J Nurs Stud. 2010;47(10):1274-82.

\section{Submit your next manuscript to BioMed Central and we will help you at every step:}

- We accept pre-submission inquiries

- Our selector tool helps you to find the most relevant journal

- We provide round the clock customer support

- Convenient online submission

- Thorough peer review

- Inclusion in PubMed and all major indexing services

- Maximum visibility for your research

Submit your manuscript at www.biomedcentral.com/submit
C Biomed Central 